\title{
Role of magnetic resonance imaging in organ-preserving strategies for the management of patients with rectal cancer
}

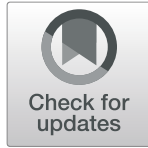

\author{
Cinthia D. Ortega ${ }^{1 *+}$ and Rodrigo O. Perez $2,3,4+$
}

\begin{abstract}
Total mesorectal excision has been the most effective treatment strategy adopted to reduce local recurrence rates among patients with rectal cancer. The morbidity associated with this radical surgical procedure led surgeons to challenge the standard therapy particularly when dealing with superficial lesions or good responders after neoadjuvant radiotherapy, to which radical surgery may be considered overtreatment. In this subset of patients, less invasive procedures in an organ-preserving strategy may result in good oncological and functional outcomes. In order to tailor the most appropriate treatment option, accurate baseline staging and reassessment of tumor response are relevant. MRI is the most robust tool for the precise selection of patients that are candidates for organ preservation; therefore, radiologists must be familiar with the criteria used to guide the management of these patients. The purpose of this article is to review the relevant features that radiologists should know in order to provide valuable information during the multidisciplinary discussion and ultimate management decision.
\end{abstract}

Keywords: Rectal cancer, Organ preservation, MRI staging

\section{Key points}

- Baseline MRI staging can identify early lesions that may be appropriate candidates for organ-preserving strategies

- MRI may provide objective information regarding appropriateness of sphincter-preserving procedures

- Good radiological response to neoadjuvant treatment identified by post-treatment MRI may select appropriate candidates to organ-preserving strategies

\section{Introduction}

Total mesorectal excision (TME) with or without neoadjuvant chemoradiation (nCRT) has been the cornerstone of rectal cancer management for the last decades, leading to significant improvement in oncological outcomes by reducing local recurrence rates [1-4]. Unfortunately,

\footnotetext{
* Correspondence: cinthia.ortega@hc.fm.usp.br

Cinthia D. Ortega and Rodrigo O. Perez contributed equally to this article.

${ }^{1}$ School of Medicine, Radiology Department, University of São Paulo, Travessa da Rua Dr. Ovídio Pires de Campos, 75, São Paulo 05403-010, Brazil

Full list of author information is available at the end of the article
}

substantial risk of perioperative morbidity comes along with this radical procedure $[5,6]$. Impairment on quality of life secondary to sexual and urinary dysfunction, poor fecal incontinence scores, low anterior resection syndrome, and the possibility of a permanent stoma are some problems the patients often face after treatment $[7,8]$.

In the past few years, concerns of the negative effects of treatment led surgeons to challenge the role of the radical surgical procedure for early-stage tumors or for good responders after nCRT [9-12]. As an alternative to TME, superficial tumors with low risk of lymph node dissemination could be managed by local excision with no radiotherapy [13] or after nCRT in the setting of good clinical response $[12,14]$. In very selected patients who achieve a complete clinical response after nCRT, a strict surveillance program without immediate surgery ("watch-and-wait") may lead to good oncological and functional outcomes $[9,10]$.

Magnetic resonance (MRI) with high-resolution T2-weighted images plays a key role in the decision management strategy of these patients. First, MR has become a routine practice for primary staging of rectal 


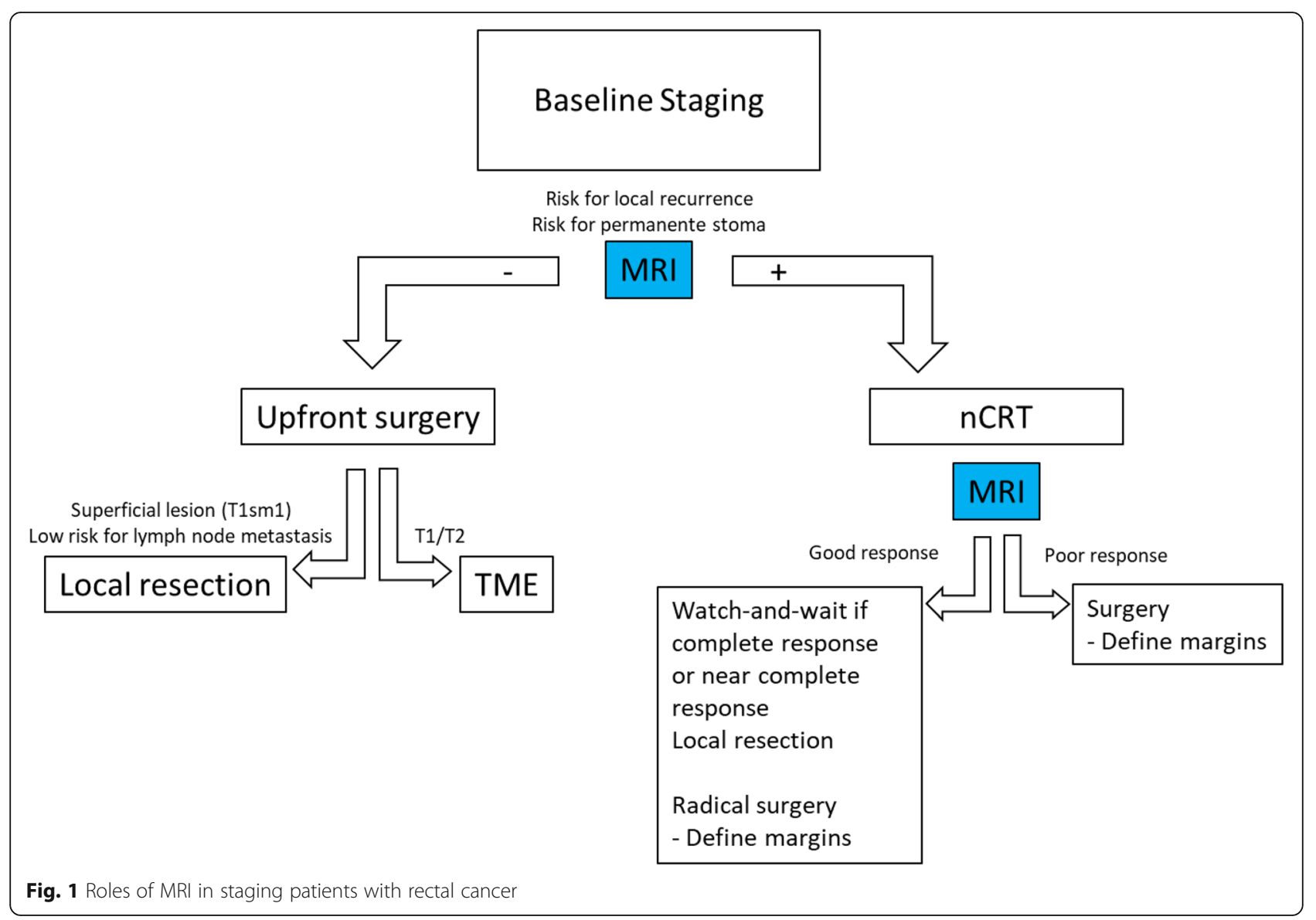

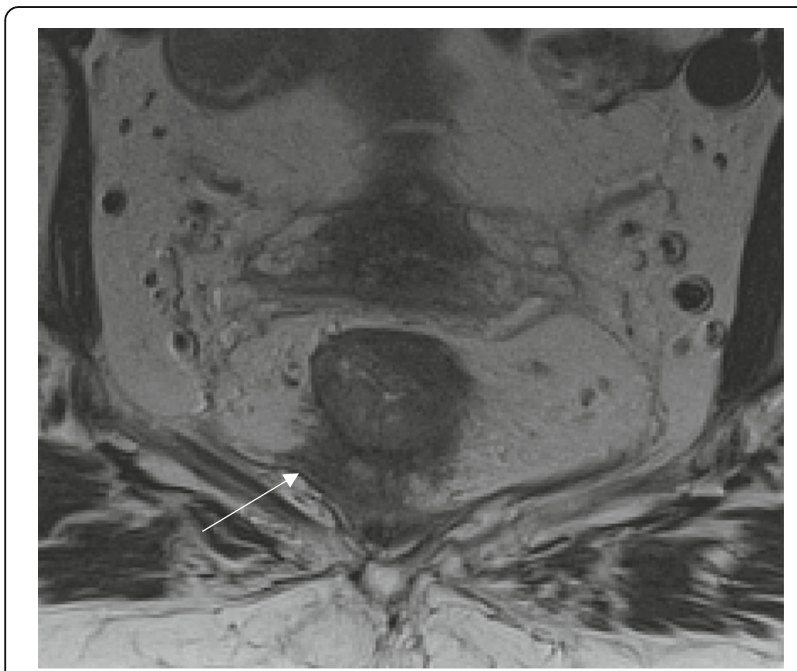

Fig. 2 Mesorectal fascia status. High-resolution axial T2WI shows a semiannular tumor infiltrating the mesorectal fat and threatening the mesorectal fascia (arrow)

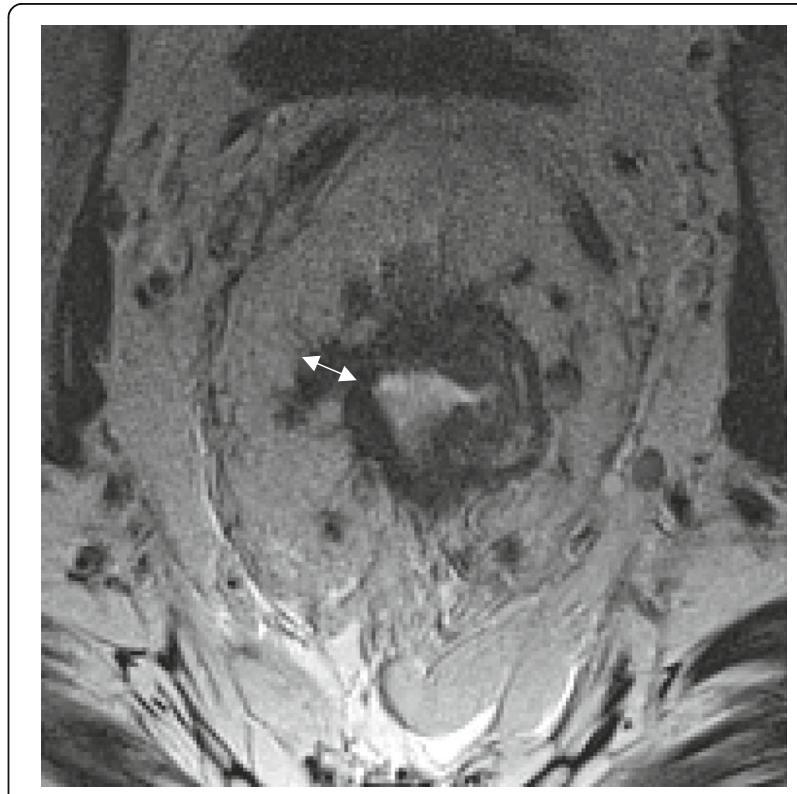

Fig. 3 T3 substage. High-resolution axial T2WI shows an annular tumor that extends beyond the muscularis propria. The measurement of the 9-mm spread was taken at the infiltrative border of the lesion at 9 o'clock (arrow) 
cancer $[15,16]$. Critical features at baseline MR staging will aid in the appropriate selection of candidates to be managed by upfront local excision, TME, or by preoperative neoadjuvant therapy $[17,18]$. Among patients undergoing the latter strategy, evaluation of response by MR restaging may be critical in assisting surgeons planning a clear-margin resection [19-22]. In addition, MRI restaging may also play a role in selecting ideal candidates for less radical approaches including local excision or watch-and-wait (Fig. 1). The present review details the use of MRI in the optimal selection of definitive surgical or non-surgical treatment for patients with rectal
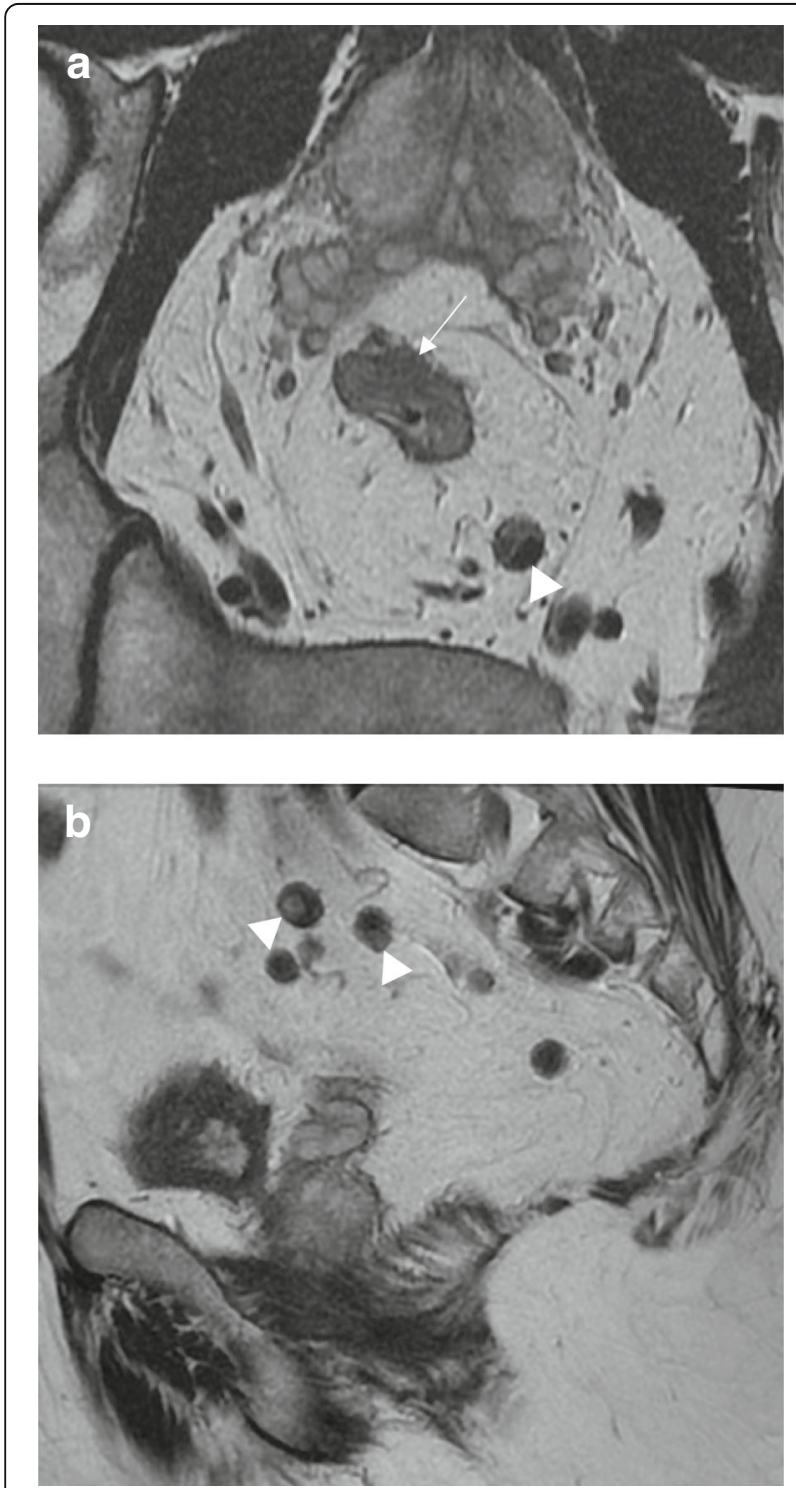

Fig. 4 Lymph node staging criteria. a High-resolution axial T2WI shows a semiannular anterior tumor (arrow) and a mesorectal involved lymph node showing mixed signal intensity (arrowhead). b Highresolution sagittal T2WI shows other involved lymph nodes with mixed signal intensity (arrowheads) cancer. The topic is particularly relevant when it comes to rectal tumors lying below the peritoneal reflection. In this setting, surgical treatment is significantly more complex and associated with higher rates of functional consequences. Here, we detail a review of pivotal staging information that radiologists must be aware of to provide valuable data for multidisciplinary discussion during the decision management process of these patients.

\section{Initial staging}

Initial locoregional rectal cancer staging aims to select patients with either high risk for local recurrence features or high risk for a permanent stoma. Both groups of patients may benefit from nCRT. In contrast, patients with early tumors can be safely managed by upfront surgery (TME). MRI is the most robust tool to detect these relevant risk factors, and proper scans are capable of detecting poor-prognosis criteria that should guide the management decision of these patients $[17,23]$. MRI should be able to identify: involvement or threatening of the mesorectal fascia, T3 lesions that extend more than $5 \mathrm{~mm}$ beyond the muscularis propria layer, the presence of $\geq 3$ metastatic mesorectal lymph nodes (N2), extramural vascular invasion (EMVI), and pelvic side lymph nodes.

As previously described, baseline staging of rectal tumors should include $[15,16,23,24]$ :

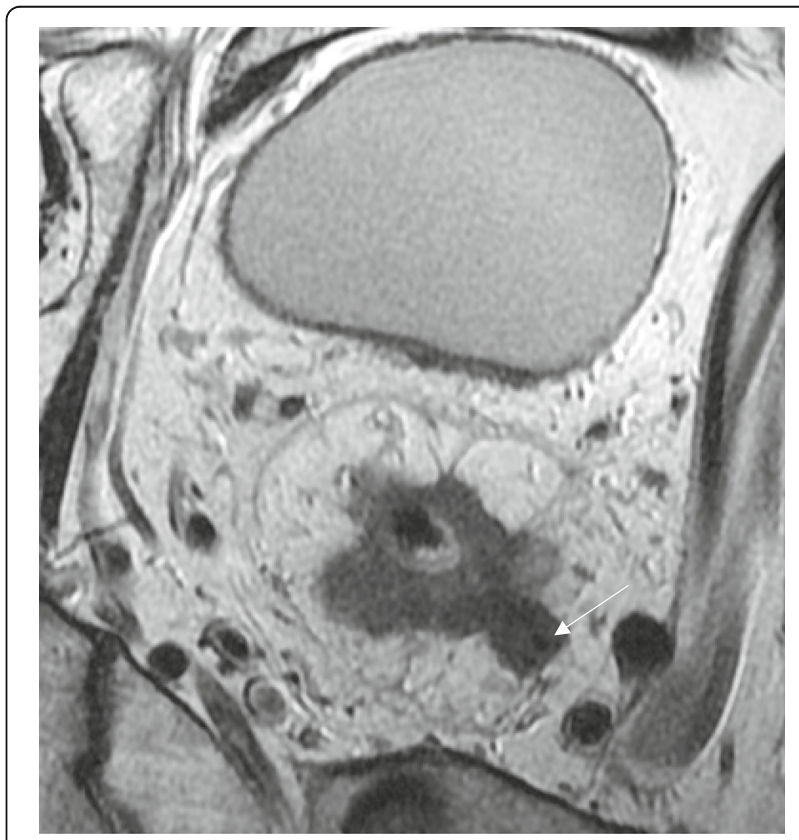

Fig. 5 Extramural vascular invasion. High-resolution axial T2WI shows an annular tumor infiltrating the mesorectal fat. A mesorectal vessel flow void (arrow) is involved by nodular extension of tumoral signal intensity beyond the muscularis propria 
- Evaluation of the mesorectal fascia: if tumor, EMVI or deposits are within $1 \mathrm{~mm}$ of the mesorectal fascia, the latter should be considered involved (Fig. 2)

- T3 substage: T3 tumors should be subclassified according to the maximal depth of spread into the mesorectal fat. That should be measured from the edge of the outermost muscularis propria layer (Fig. 3)

- Lymph node staging: morphological criteria used for mesorectal or pelvic side node positivity include border irregularity or mixed signal intensity (Fig. 4)

- Extramural venous invasion: it is depicted as tumor signal into or along mesorectal vessels, which may lose the characteristic flow-void on T2WI, that show enlargement or contour irregularity (Fig. 5)

When none of these known risk factors are present, patients can be managed by TME surgery alone provided
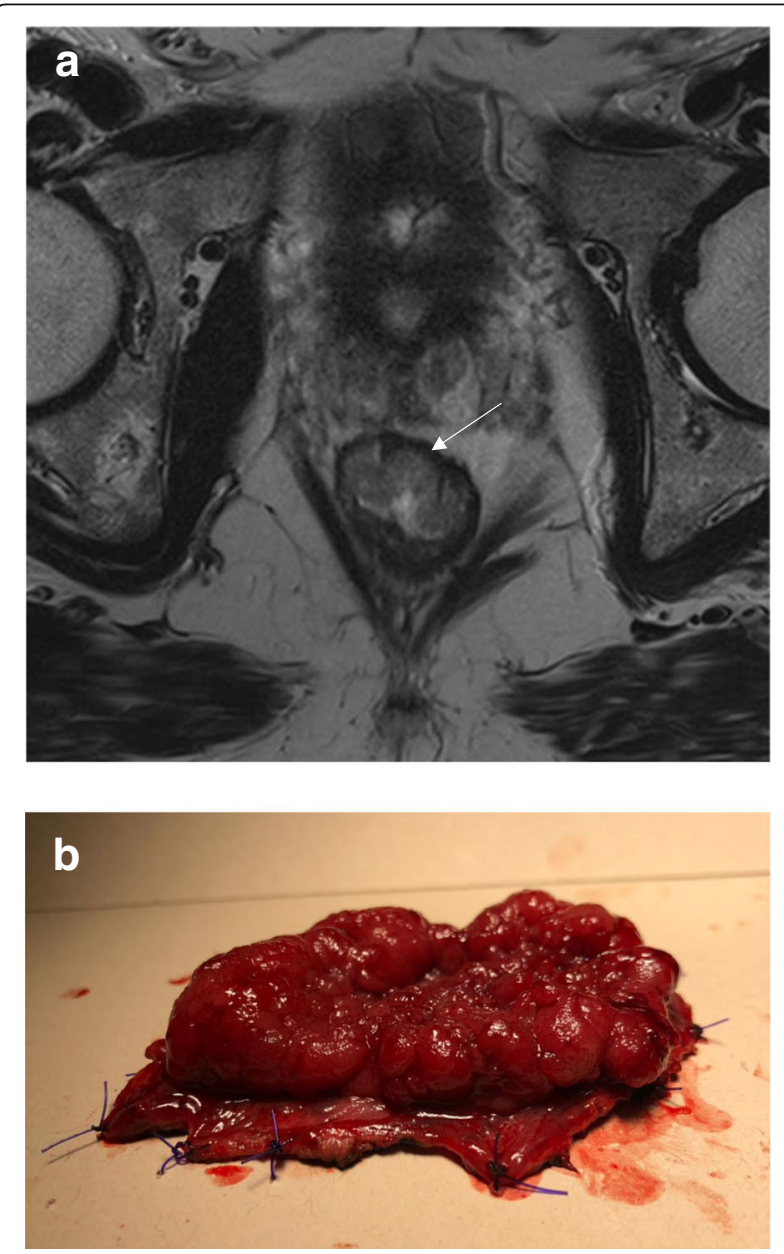

Fig. 6 Early rectal cancer staging. a High-resolution axial T2WI shows a semiannular low lying lesion extending from 10 to 3 o'clock confined to the rectal wall with no signs of invasion of the muscularis propria (arrow). The lesion was staged as mrT1N0, and local excision was performed. b Surgical specimen. The resected specimen after local excision. Histopathological analysis diagnosed adenoma there is good surgical technique and an intact TME specimen [18].

\section{Surgical alternatives: TME or local excision}

TME is a surgical procedure that completely removes the rectum harboring the primary cancer along with the mesorectal fat containing lymph nodes, vessels, and tumor deposits [25, 26]. By removing the entire and intact mesorectum with clear circumferential resection margins (CRM), the risk of local recurrence decreases even in patients with nodal or extramural vascular spread $[27,28]$.

In contrast, transanal local excision is a procedure that exclusively removes the primary tumor by a full-thickness incision of the rectal wall in the area bearing the primary tumor. The procedure is currently more frequently performed using modern endoscopic platforms allowing for higher rates of margin negative and non-fragmentation of the specimen [29]. During local excision, there is no formal removal of draining lymph nodes, even though eventually a few lymph nodes may be recovered from the resected specimen present in the surrounding perirectal fat [30]. Therefore, only early rectal lesions confined to the bowel wall and showing minimal risk for lymph node metastases are appropriate candidates to local excision as a definitive and curative procedure. The greatest advantage of this procedure is the avoidance of the potential mortality and morbidity of

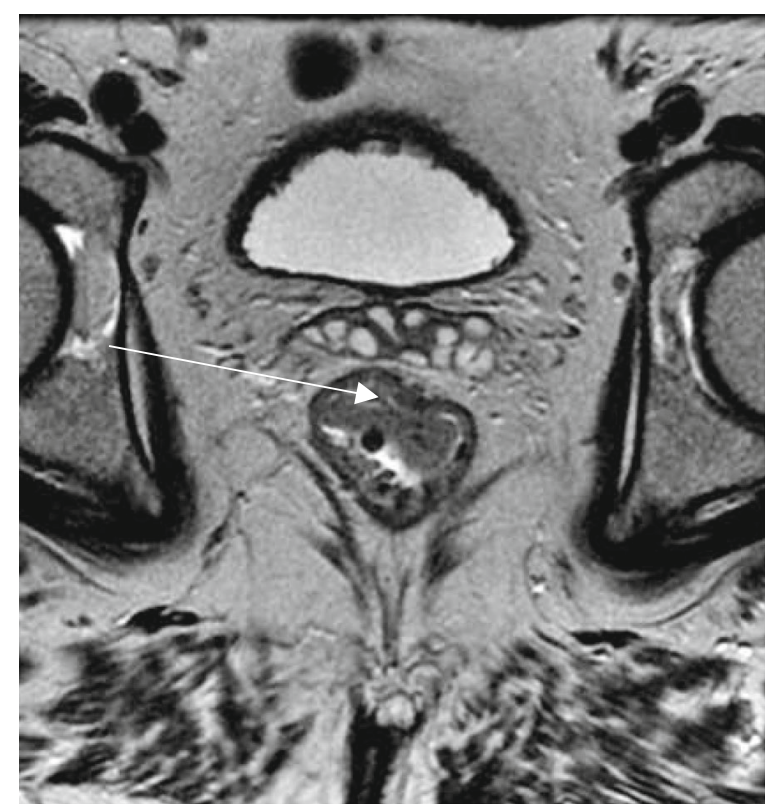

Fig. 7 The high-signal intensity of the submucosa. High-resolution axial T2WI shows a semiannular low-lying lesion extending from 10 to 1 o'clock confined to the rectal wall with no signs of invasion of the muscularis propria and preserved high-signal intensity of the submucosal layer (arrow). The lesion was staged as mrT1NO 
radical surgery while maintaining acceptable oncological outcomes [13, 29] (Fig. 6).

\section{Candidates for local excision}

Here, the primary purpose of staging is the identification of unfavorable features in order to rule out a local procedure without formal mesorectal excision. Primary depth of tumor infiltration (T-stage), submucosal lymphovascular invasion, budding and tumor grade are known histopathologic predictors of mesorectal nodal metastases $(\mathrm{pN}+)[13,31]$. Apart from histological criteria, available only after resection, imaging may provide the identification of features that may also predict a poor outcome after local excision. The presence of involved lymph nodes, extramural vascular invasion, and tumors invading beyond the muscularis propria $(\geq \mathrm{pT} 3)$ are all clear contraindication for a local procedure as a definitive treatment in rectal cancer patients with curative intent $[15,32]$.

The risk of lymph node involvement among pT2 lesions is also quite considerable, so most T2 lesions should be preferably not managed by local excision alone as a definitive curative intent treatment modality $[31,33]$. There is some data supporting the use of local excision followed by adjuvant chemoradiation in small and superficial pT2 cancers [14]. However, TME offers the best chances of cure among most of these patients.

Due to the absence or low risk of $\mathrm{pN}+$, local excision is the preferred treatment alternative for the management of adenomas, in situ adenocarcinoma, and select T1 lesions. Sessile T1 lesions can be subclassified using the Kikuchi submucosal staging system into three levels: sm1 lesions infiltrate up to the upper third of the submucosa, sm2 up to the middle third, and sm 3 up to the lower third [34]. Alternatively, precise measurement of depth invasion may also provide accurate identification of patients at lower risk for $\mathrm{pN}+$. Patients with $\leq 1000 \mu \mathrm{M}$ of depth of tumor invasion $(\mathrm{sm} 1)$ are considered appropriate candidates for local excision alone [35]. Risk stratification shows that $\mathrm{T} 1 \mathrm{sm} 3$ lesions are associated with nodal spread at almost similar rates to $\mathrm{T} 2$ lesions. Therefore, $\mathrm{T} 1 \mathrm{sm} 1$ tumors are the ones associated with lower risk of nodal metastases
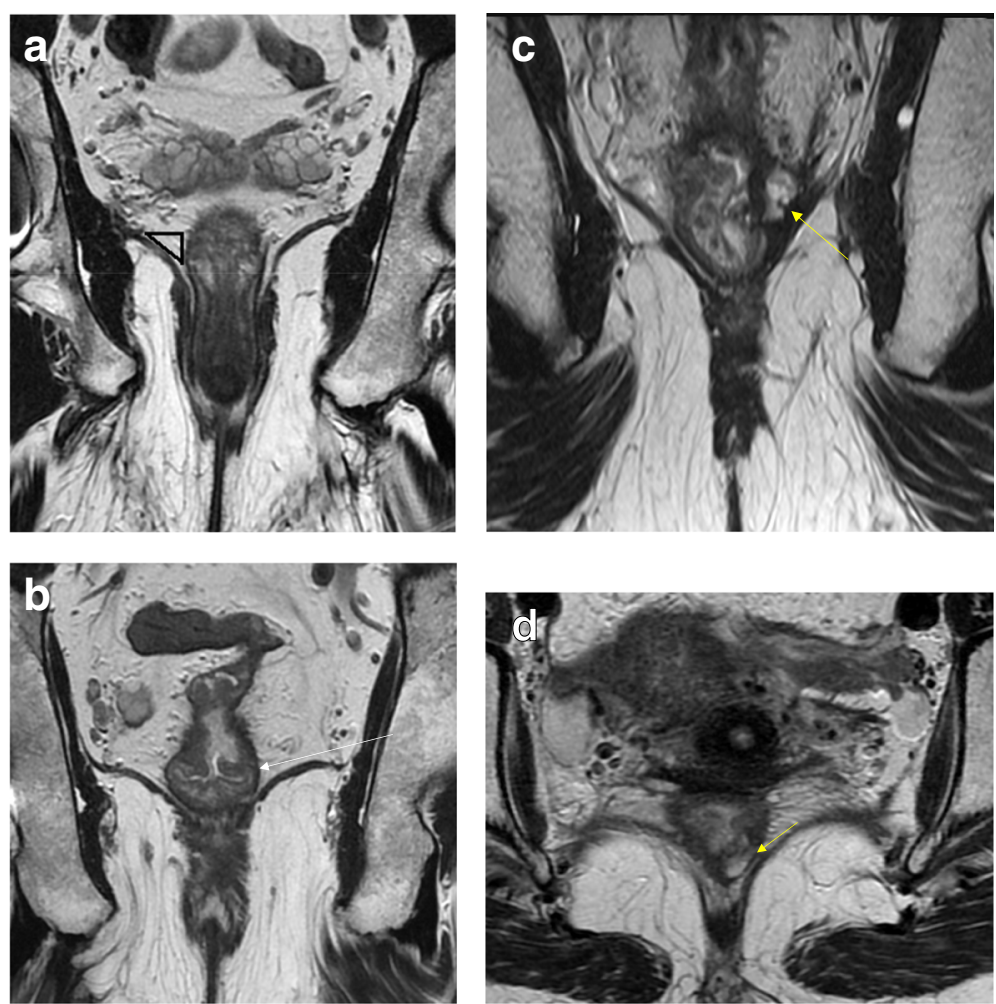

Fig. 8 The assessment of the intersphincteric plane safety. a Coronal T2Wl shows the normal anal canal anatomy. The distal tapering of the mesorectal fat is shown by the black triangle that delineates the fat content on the upper portion or the dissection plane when low anterior resection is performed. $\mathbf{b}$ Coronal T2WI shows the distal edge of the lesion (arrow) above the intersphincteric plane. Low anterior resection is possible with no risk of margin positivity at this level. c Coronal T2WI shows the distal edge of the lesion lying in the plane of the levators. There is lateral spread with mucinous content on the left, threatening the intersphincteric plane (arrow). d High-resolution axial T2WI shows a residual low-lying lesion partially invading the muscularis propria (arrow). Intersphincteric resection would be safely performed. A clear resection margin was achieved 
and recurrence and that can be safely managed by local excision alone [36].

\section{Staging}

Clinical selection of this specific subgroup of early lesions is challenging. Available options to staging early rectal tumors are MRI, endorectal ultrasound, and magnifying colonoscopy or image-enhanced endoscopy [37, 38]. Briefly, endorectal ultrasound is capable of distinguishing between $\mathrm{T} 1$ and $\mathrm{T} 2$ lesions with good overall accuracy, and the main limitations include large lesions, polyps, or lesions lying on the upper third of the rectum. Endoscopic evaluation of the pit pattern of rectal lesions is one of the most accurate methods to preoperatively distinguish between a benign or a malignant lesion. In addition, it provides information regarding deep submucosal invasion in superficial tumors [38]. Precise endoscopic findings and patterns associated with distinct histological findings are provided elsewhere and are beyond the scope of this review.

MRI may help evaluate the presence of extramural disease with good specificity. It is the most accurate method to evaluate tumor extension beyond the muscularis propria and extramural vascular invasion and shows good positive predictive values in assessing mesorectal nodes [17, 39, 40]; however, distinguishing between T1 and T2 lesions is sometimes not straightforward. Considering that $\mathrm{T} 1$ classification is not enough to guide treatment, subclassification of $\mathrm{T} 1$ is required. It has been shown that a visible measurement of $1 \mathrm{~mm}$ or more of preserved high-signal intensity of the submucosa (Fig. 7) can be used as a predictor of partial submucosal invasion [32]. In this framework, using MRI to distinguish between $\mathrm{T} 1$ and $\mathrm{T} 2$ lesions may be challenging, but distinguishing between early T1sm1-2 prone to local excision and T1sm3/T2 lesions that are not ideal candidates for local resection may be more accurate.

Overall, the roles of MRI when evaluating early rectal tumors if local resection is considered are:

1) Detection of any unsuspected mesorectal disease-positive nodes and/or vascular invasion

2) Evaluation of T-stage-submucosal high signal intensity preservation to exclude T1sm3/T2 lesions

If there is neither mesorectal disease nor deep infiltration of the rectal wall seen on the MRI, local excision can be considered an appropriate alternative. Here, local excision may act as an excisional biopsy. If histopathology confirms preoperative staging ( $<\mathrm{pT} 1 \mathrm{sm} 3)$, local resection may be considered curative. However, if histopathology shows $\geq \mathrm{pT} 1 \mathrm{sm} 3$, lymphovascular invasion, budding, or other unfavorable features, additional treatment after local excision may still be necessary [13, 33]. Alternatives for additional treatment may include completion of TME or adjuvant/postoperative chemoradiation (CRT) [33, 41, 42].

\section{Sphincter preservation}

According to the location and staging, low rectal tumors that undergo surgery may require abdominoperineal resection (APR) with a permanent stoma or coloanal anastomosis with occasionally poor functional outcomes $[8,32,43]$. Traditionally, surgeons would make the decision between an APR or a restorative procedure with sphincter preservation based on the distance of the tumor from the sphincter complex and preoperative function. Patients with already preoperative incontinence were obviously considered for APR. However, from an oncological standpoint, the ability to achieve a safe distal margin with no direct invasion of the sphincters was considered the sole required condition for a sphinctersaving procedure. This assessment was almost universally done through simple clinical or digital rectal examination. Currently, however, MR offers the opportunity to assess more accurately the integrity of the surgical plane required for organ preservation [44, 45]. During TME with sphincter preservation, the surgeon will have to dissect between the mesorectal plane and the levator muscles. As the plane progresses distally, the mesorectal plane tapers and becomes closer to the levator ani muscles. The integrity of such plane is crucial for obtaining

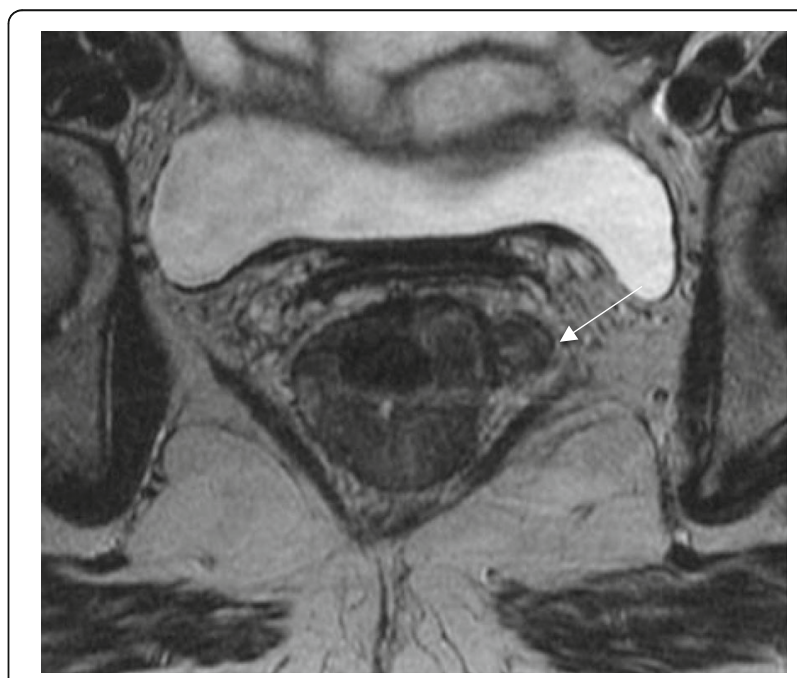

Fig. 9 Low rectal cancer staging. High-resolution axial T2WI shows a semiannular lying lesion with tumor deposit extending to the mesorectal fat and threatening the mesorectal fascia (arrow). The lesion was staged as mrT3 with positive mesorectal fascia and positive EMVI. The patient was sent to nCRT 
an R0 mesorectal plane dissection with sphincter preservation. This is accurately provided by MR [46] (Fig. 8). A recent classification of distal rectal tumors provided by MRI and clinical assessment describes four types and their preferred surgical management strategies. The first I-III subtypes (supra-anal, juxta-anal, and intra-anal) may provide the opportunity for sphincter preservation. Type IV (transanal) is best suited for APR [45].
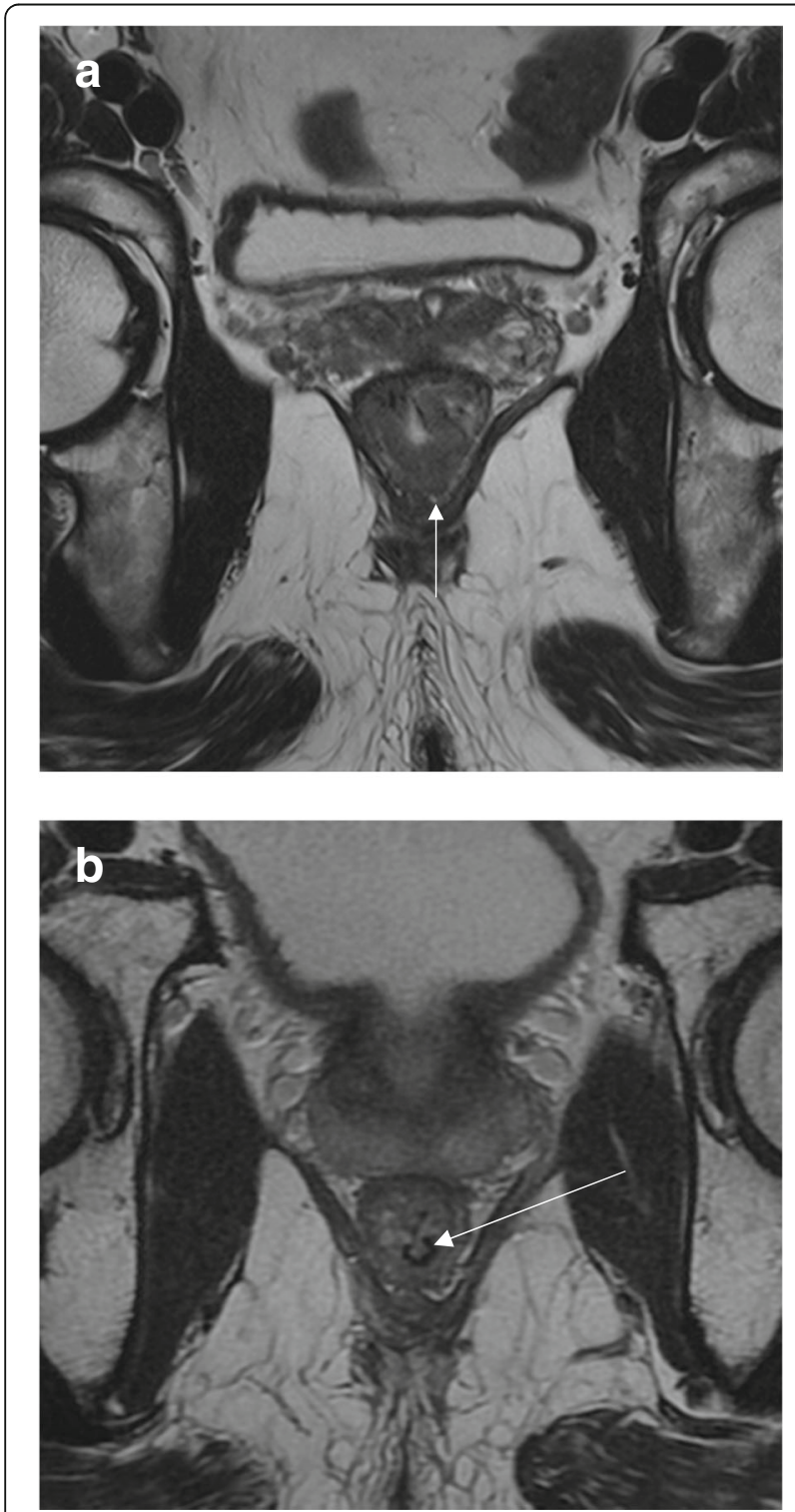

Fig. 10 Early low rectal cancer staging. a High-resolution axial T2WI baseline staging shows a low-lying posterior lesion extending from 2 to 10 o'clock confined to the rectal wall with no signs of intersphincteric plane involvement (arrow). The lesion was staged as mrT2NO, and the patient was referred to nCRT in an attempt to achieve CCR. $\mathbf{b}$ Restaging 12 weeks after neoadjuvant CRT shows a low SI scar (arrow). A watch-and-wait approach was attempted. Two years of follow-up show no regrowth

\section{Organ preservation}

nCRT has been used with the purpose of avoiding local recurrence by downstaging and downsizing locally advanced rectal tumors resulting in increased rates of clear resection margins [1,2]. A proportion of these patients will achieve complete pathological response (pCR) with no tumor seen in the surgical specimen after nCRT. This has raised the question to whether surgery was necessary or otherwise resulted in overtreatment of this subgroup of patients, particularly when a permanent stoma is required [9]. For these reasons, patients who achieve complete clinical response (cCR), with no visible residual tumor when assessed by digital rectal examination or endoscopy, have been managed without immediate surgery $[47,48]$. A significant proportion of patients that achieve $\mathrm{cCR}$ may reflect complete pathological response (pCR). Deferring ultimate surgical management of these patients with cCR or apparent complete pathological response is currently considered an acceptable alternative in order to avoid potentially unnecessary morbidity and mortality of radical surgery and still achieve excellent/ similar oncological outcomes [47, 49-51].

Several features may influence the development of a cCR including treatment-related and tumor-related features. Baseline staging features have been considered a predictor of long-term outcome after organ preservation. Depth of tumor penetration seems to correlate directly with the risk of developing tumor regrowth after initial "apparent" complete clinical response and non-operative management [52, 53]. The chances of successful organ preservation are higher for early baseline tumors (mrT2)

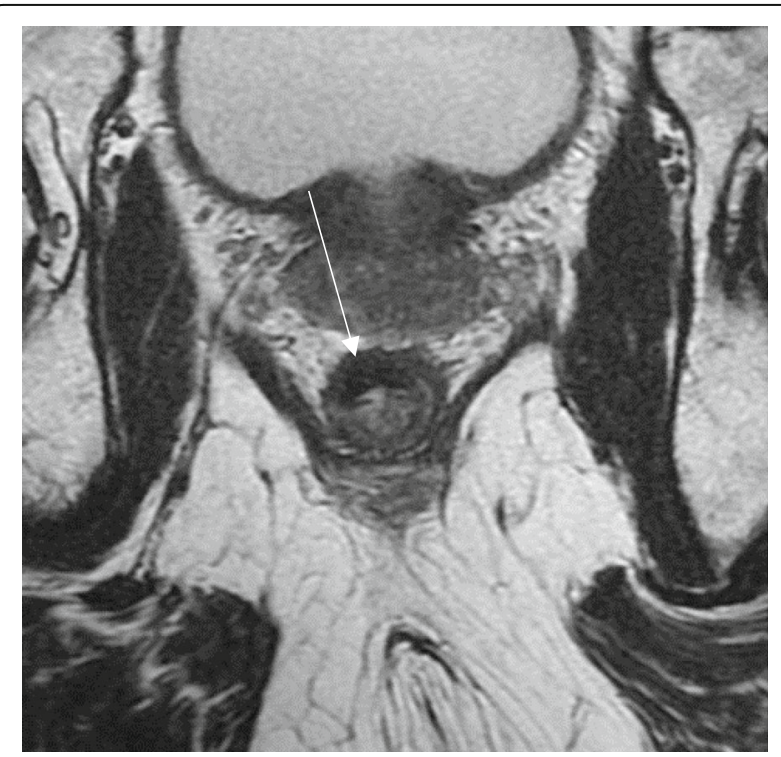

Fig. 11 Watch-and-wait approach. High-resolution T2WI restaging shows a low signal intensity fibrotic full-thickness scar extending from 9 to 12 o'clock (arrow). Four-year follow-up showed no regrowth 
and lower for more advanced baseline lesions (mrT3 or mrT4) $[11,53]$. In contrast, nodal disease at baseline has not been associated with lower rates of successful organ preservation [54].

In this context, MRI plays a role in the selection process of patients who are ideal candidates to this approach. Tumors with no adverse features/"good tumors" may be managed by upfront surgery without neoadjuvant CRT, (T2 or T3a/bN0-1 tumors), whenever the surgical alternative would otherwise require an APR or an ultra-low anterior resection (associated with poor anorectal function) [55]. This particular subgroup of patients could be staged and guided to neoadjuvant therapy as an attempt to achieve $\mathrm{CCR}$ and undergo a non-operative management pathway. Here, the purpose of nCRT is not to decrease the rates of a positive margin, but to achieve primary tumor regression, possibly avoid surgery and to improve functional outcomes. Although early cT3 lesions may also achieve $\mathrm{cCR}$, retrospective analysis indicates that the risk of early regrowths within the first year of follow-up is increased when compared to cT2 lesions [52]. Therefore, distinguishing between cT2 vs cT3a low rectal tumors may be relevant if organ preservation is considered.

In addition, when chemoradiation is considered for the purpose of achieving cCR, treatment-related features may become relevant. There is also data to suggest that higher radiation therapy doses ( $\geq 50.4 \mathrm{~Gy}$ ) and additional chemotherapy cycles (consolidation chemotherapy) may increase the chances of primary tumor regression [56, 57]. The benefits of more aggressive treatment here seem to be associated with baseline staging features $[11,58]$. Therefore, primary staging and chances of achieving $\mathrm{CCR}$ after treatment may aid multidisciplinary team decision regarding optimal radiation therapy and chemotherapy regimens taking the possibility of organ preservation into account.

In summary, important information provided by MRI when evaluating low rectal tumors include:
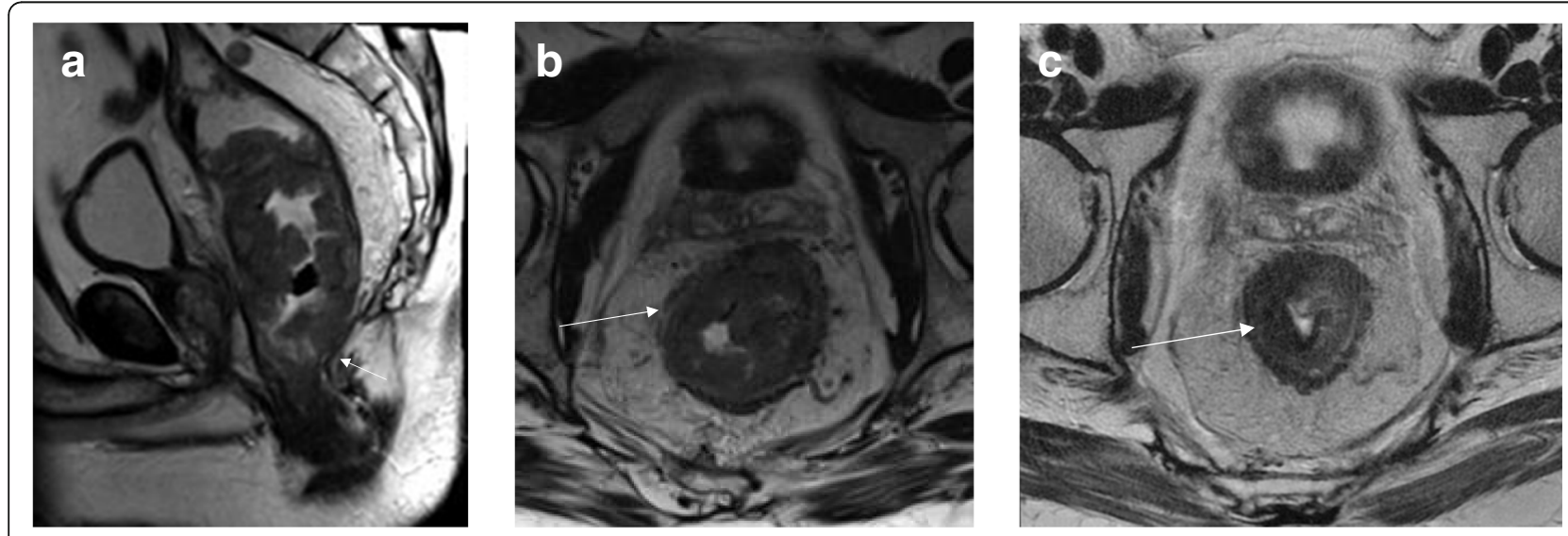

\section{d}
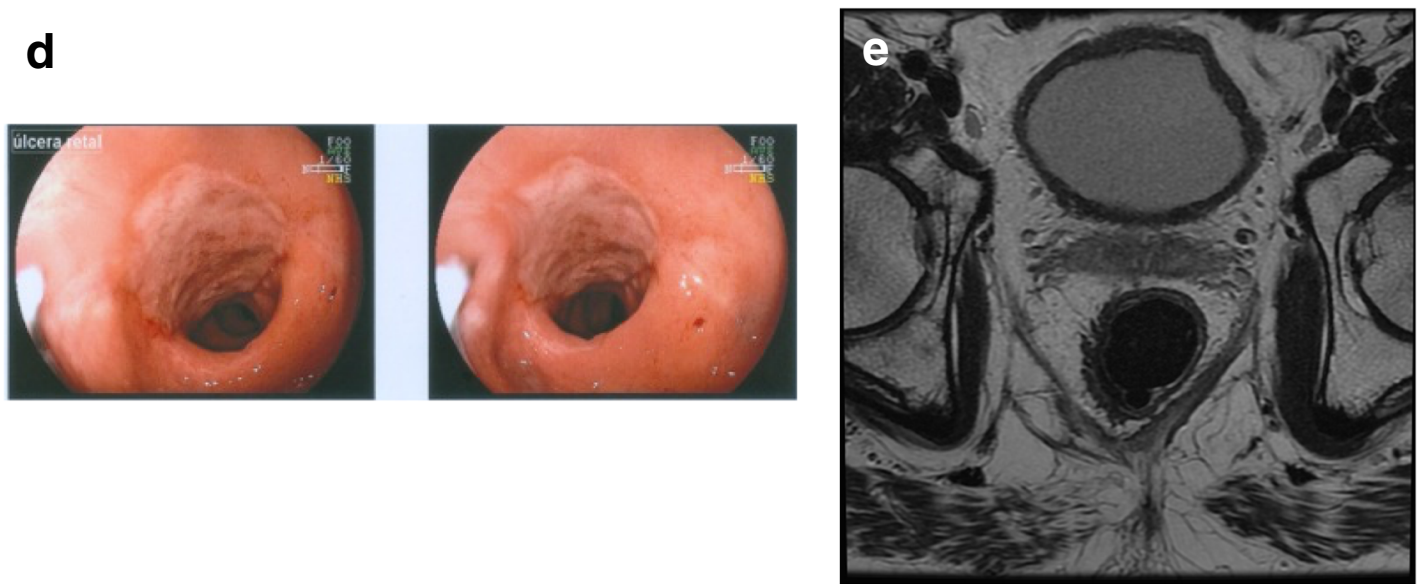

Fig. 12 Long-time intervals of reassessment. a Sagittal T2WI shows the baseline staging of a low rectal tumor with the distal margin lying below the intersphincteric plane (arrow). b Axial T2WI shows the semiannular lesion (arrow). c Restaging after 10 weeks showed a good response with predominant low-signal intensity within the lesion (arrow). d Proctoscopy showing good but incomplete response with residual ulceration. e Reassessment after longer intervals showed evidence of ongoing response to CRT. Follow-up exams after 22 weeks revealed findings consistent with complete clinical response 
1) Staging and defining risks of a positive CRM to guide nCRT (Fig. 9)

2) Staging early lesions not at risk of positive CRM, but that may benefit from nCRT tailored to achieve cCR (Fig. 10)

3) Determination of intersphincteric plane invasion, suggesting the need for APR

\section{Restaging after radiotherapy}

Response to nCRT can be assessed according to institutional protocols, in general varying from 6 to 12 weeks after the end of radiotherapy [59]. Poor responders usually undergo surgery, and the main role of MRI in this situation is road-mapping the resection planes so that the decision of the most appropriate surgical approach capable of achieving a clear-margin resection is taken [19, 21, 22, 60].

In contrast, the population showing a good response to nCRT evaluated by digital exam, endoscopy, and MRI criteria might be selected to less radical options [48, 61-63]. Good responders can be selected to local excision or to clinical and imaging reassessments ("watch-and-wait") in a non-operative approach (Fig. 11). In this latter approach, no immediate surgery is performed until the presence of viable tumor is confirmed by either digital rectum exam (DRE), endoscopic, or imaging evidence of tumor regrowth [64-66]. If regrowth is detected, then radical surgery may be unavoidable.

When the watch-and-wait strategy was first proposed by Habr-Gama et al., only patients that achieved complete clinical response were eligible, meaning that strict criteria of endoscopic and clinical response were to be followed without immediate radical surgery $[9,48]$. This practice, initially performed by a single center in Brazil, is now performed in several centers, which allows more data to be published $[47,53,67,68]$. As data related to the follow-up of patients has increased, it is now proposed that near-complete responders may also be candidates to deferral of surgery $[66,69]$. This has been supported by the observation that a significant proportion of patients only achieve CCR (strict criteria) after longer than 8-12 weeks intervals from radiation completion (Fig. 12) [70].

\section{Tumor regression grade (TRG), diffusion-weighted MR imaging (DWI), and staging}

Lesions with complete response after radiotherapy show either a normal rectal wall, whitening of the mucosa with or without some telangiectasia when clinically assessed by endoscopy or DRE [48]. Residual mucosal abnormalities may be present even in pCR, making
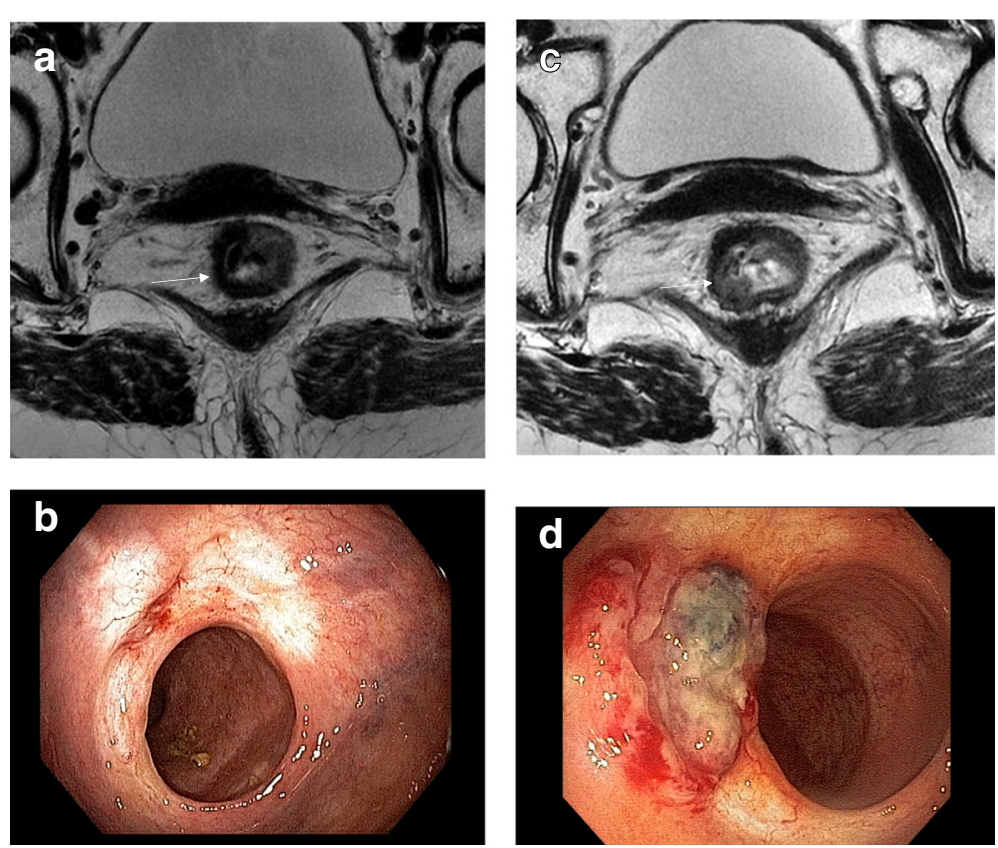

Fig. 13 Luminal regrowth detected by MRI and endoscopy. a High-resolution T2WI restaging after 8 weeks of completion of CRT shows a low signal intensity fibrotic full-thickness scar extending from 5 to 12 o'clock (arrow). The patient was referred to watch-and-wait. b The endoscopic view of the treated lesion after 8 weeks of completing CRT shows whitening of the mucosa with some telangiectasia and no significant residual ulceration. c Follow-up after 16 months of completion of CRT shows increased signal intensity where the scar was previously seen from 6 to 9 o'clock (arrow). The patient was referred to salvage resection with total mesorectal excision. A clear margin resection was performed. $\mathbf{d}$ The endoscopic view of the treated lesion after 16 months of completing CRT shows evident tumor regrowth 
endoscopic assessment alone insufficient to select possible complete responders properly [71].

When it comes to radiological assessment, good responders show T2WI low signal intensity fibrosis replacing the tumor within the rectal wall or even beyond $[49,60,72]$. The amount of fibrosis can be estimated by MRI through the TRG classification. Results of the MERCURY trial show good correlation between mrTRG and oncologic outcomes; therefore, the amount of fibrosis seen on MRI is a biomarker of response and better oncological results after radical surgery [73]. Good responders show predominant sign of fibrosis on T2WI MRI, with either no signal of tumor or minimal findings. Those lesions are classified as TRG1-2 [49].

DWI is a functional technique used to detect tissues with increased cellularity, which causes restriction to the diffusion of water molecules, resulting in high-signal intensity seen by this sequence. Thus, DWI is useful to detect residual cancer tissue after nCRT and may add information regarding tumor response by increasing the confidence rate of radiologists and increasing interobserver agreement rates [74].

Restaging MRI has a role in detecting those good responders and is fundamental in detecting extraluminal disease not assessed or accessible by endoscopy or DRE-lymph nodes, extramural venous invasion, tumor deposits, lateral pelvic side nodes, peritoneal, or other metastatic diseases [64].

The combination of favorable clinical, endoscopic, and imaging criteria may suggest that good responders should be reassessed and not be immediately sent to surgery-or even managed by transanal local excision-if organ-preserving strategy is pursued, especially when it comes to low-lying tumors that require a permanent stoma or ultra-low anastomoses with poor functional outcomes.

\section{Interval of reassessment}

The optimal timing of reassessment after the end of radiotherapy is still controversial. Retrospective data show that long intervals between the end of nCRT and surgery may result in increased proportions of pCR [75].
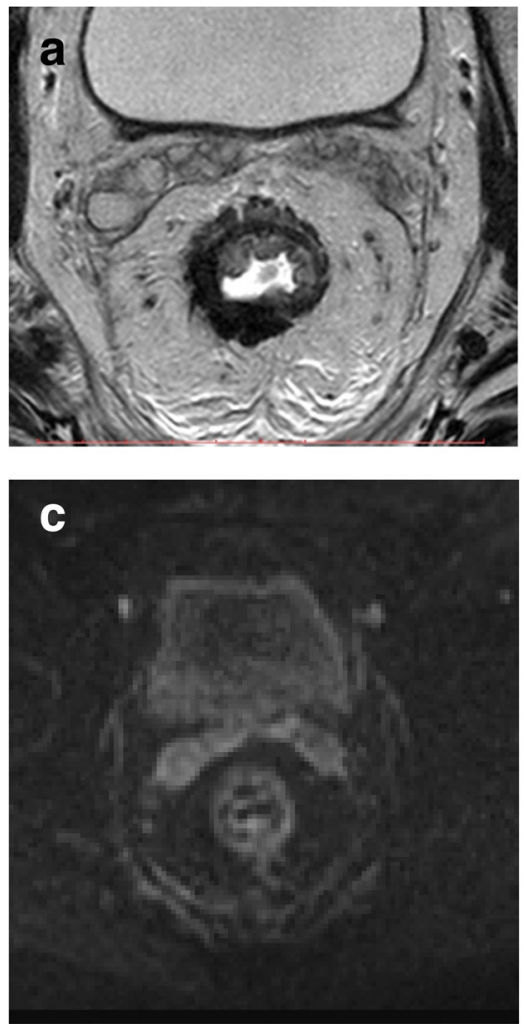

Fig. 14 Luminal regrowth detected exclusively by endoscopy. Images show a clear endoscopic view of a regrowth following initial complete clinical response with no relevant radiological findings. a High-resolution T2WI restaging axial image 16 weeks after neoadjuvant therapy shows a low signal intensity scar from 5 to 9 o'clock. Watch-and-wait was offered. b Follow-up exam after 12 months showed less extensive, from 7 to 10 o'clock persistent low signal intensity scar with no signs of regrowth. c DWI $(B=700)$ was unremarkable. $\mathbf{d}$ Endoscopy showed obvious regrowth at 12 months and the patient was sent to salvage resection. Total mesorectal excision was performed; ypT2NO with free margins was the final result 

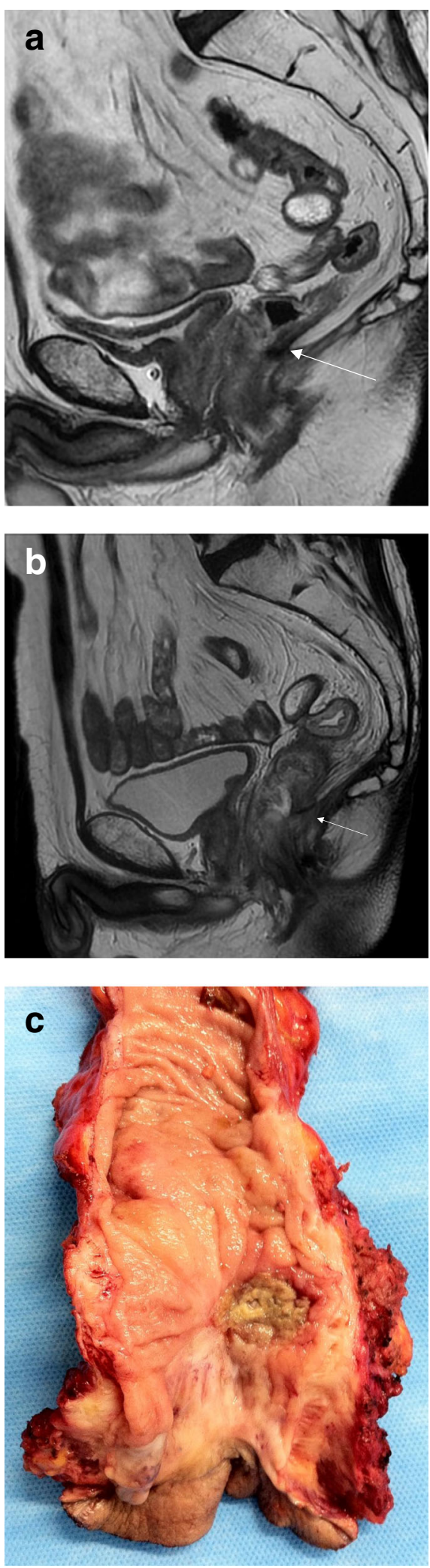

Fig. 15 Low rectal lesion with luminal and mesorectal regrowth. a High-resolution sagittal T2WI shows the posterior low signal intensity scar (arrow). b Follow-up exam after 5 months showed increased signal intensity within the scar and extension to the intersphincteric plane (arrow). c The specimen shows the luminal lesion close to the anal verge. Extralevator APR was required and performed with coccygeal resection. Final pathological examination confirmed ypT3N0 with clear $(4 \mathrm{~mm})$ circumferential resection margins (RO)

When the tumor is reassessed 6-12 weeks after the end of radiotherapy, cCR may already have occurred in some patients. In a proportion of patients, a near $\mathrm{CCR}$ may be seen with still some irregularity at DRE, a small residual ulcer or irregular wall thickening at endoscopy, or minimal tumor sign within the fibrosis $[69,71]$.

If surgical resection is performed at that time, residual tumor may be present within the specimen. Nevertheless, tumor regression may continue beyond 12 weeks, making it impossible to be sure whether further response to radiotherapy was still ongoing. Waiting longer than the 12-week interval to reassess response may result in a larger proportion of patients who achieve a cCR $[10,76]$.

A prospective multicentric randomized trial that compared the rates of pCR when patients were evaluated either 7 or 11 weeks after the end of nCRT failed to show difference between the intervals; moreover, additional morbidity was seen on the 11-week group [59]. The results of additional randomized trials evaluating tumor response after 6 or 12 weeks are awaited to further clarify the optimal timing for assessment of these patients.

\section{Follow-up and regrowth}

The purpose of follow-up or surveillance studies is to detect possible tumor regrowths after initial "apparent" complete clinical response. Most of these regrowths represent viable tumor that repopulates the area of the primary tumor within the rectal wall. The interval of required surveillance exams remains unclear. Since most regrowths occur during the first 2 years of follow-up, imaging evaluations should be more frequent during this period [53]. Endoscopy and DRE evaluate luminal regrowths. MRI is helpful to detect regrowths within the rectal wall deeper than the mucosa or exclusively (less frequent) extraluminal disease-mesorectal or extramesorectal (Figs. 13, 14, 15, 16).

Most regrowths are luminal, detected by endoscopy or DRE. MRI may also detect luminal regrowths as low signal intensity scar changes and tumor intermediate signal intensity appears. Comparison between follow-up exams is useful as changes of signal intensity within the scar may be subtle. Also, thickening of the low signal intensity scar should be regarded as an indirect sign of potential recurrence or regrowth. 

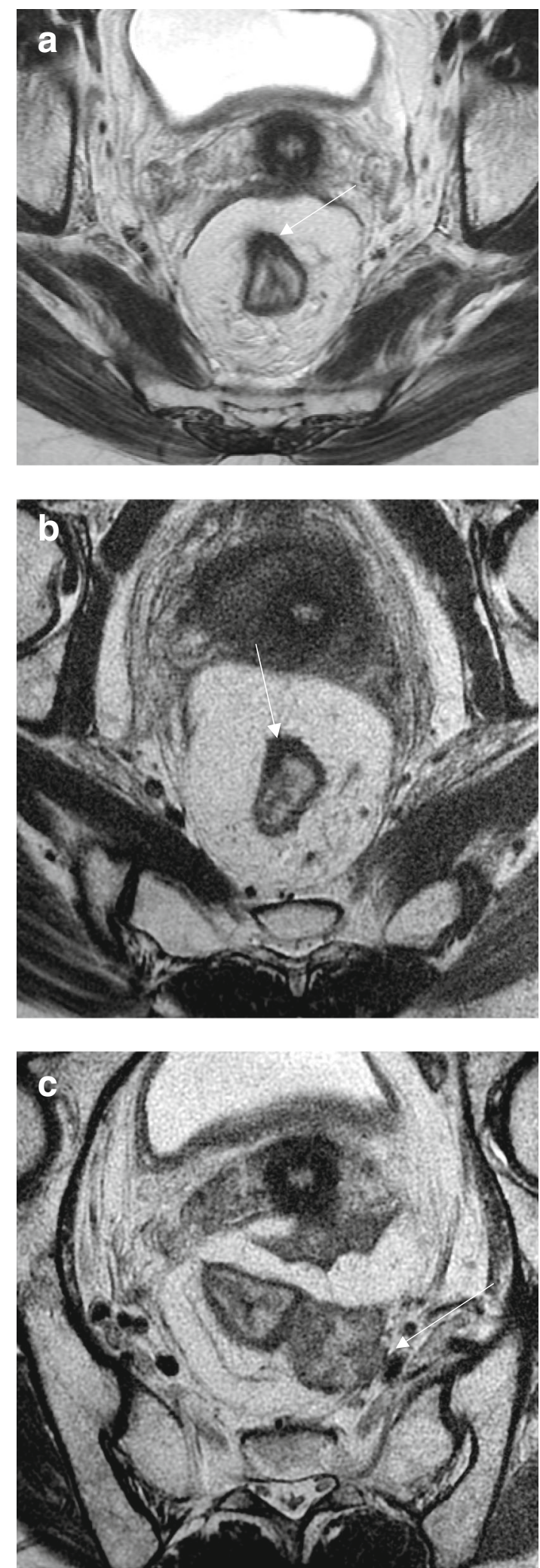

Fig. 16 Mesorectal regrowth. a Axial T2WI shows an anterior low signal intensity scar (arrow). No mesorectal disease was visible. b Follow-up exam after 12 months showed an unchanged low signal intensity scar within the anterior wall of the rectum (arrow). c A large mesorectal lymph node or deposit was visible, threatening the mesorectal fascia (arrow). Total mesorectal excision was performed (ypT0N1) with a clear (2 mm) circumferential resection margin

A retrospective analysis showed that DWI may improve the sensitivity of MRI for detecting regrowths [64]. Still, it has been the author's experience that, provided there is an appropriate follow-up, regrowths usually present with positive endoscopic and clinical findings with minimal or subtle radiological abnormalities (Fig. 14) [77].

Exceptions here include patients with ultra-low primary tumors with local regrowth or exclusive mesorectal compartment recurrences. In the former, endoscopic and clinical assessments may be considerably challenging due to the lack of proper wall distention. Here, minimal changes in thickness or in signal intensity of the scar should raise flags regarding the possibility of a regrowth even in the paucity of clinical findings. (Fig. 15).

Very few regrowths have been detected exclusively within the mesorectal compartment [77]. Examples here include any visible increase in size and appearance of newly detected lymph nodes/tumor deposits with typical morphologic changes including border irregularity and/ or mixed signal intensity (Fig. 16).

When regrowth is detected, patients are usually referred to surgical resection. The roles of MRI are staging and planning a clear-margin resection as usual.

\section{Local excision}

Local excision may be an alternative after nCRT to treat small residual lesions when no mesorectal disease is detected [12, 14] (Fig. 17). Most of the series have included patients with early-stage disease or/and small lesions at baseline and that develop significant tumor regression after treatment. Therefore, the role of imaging in upfront/baseline and during restaging for proper selection of these patients is both significant.

Local excision here may act as an excisional biopsy when there is "near complete response." Resected specimens showing unfavorable pathological features (урT $\geq$ 2 , etc.) are often recommended completion (also known as "prophylactic") TME for the risk of local recurrence and its associated poor oncological outcomes [78, 79].

Even though local excision may be considered appropriate after pathological examination of the resected specimen, local recurrences are still a concern. MRI may be helpful in detecting recurrences and plan radical surgical 

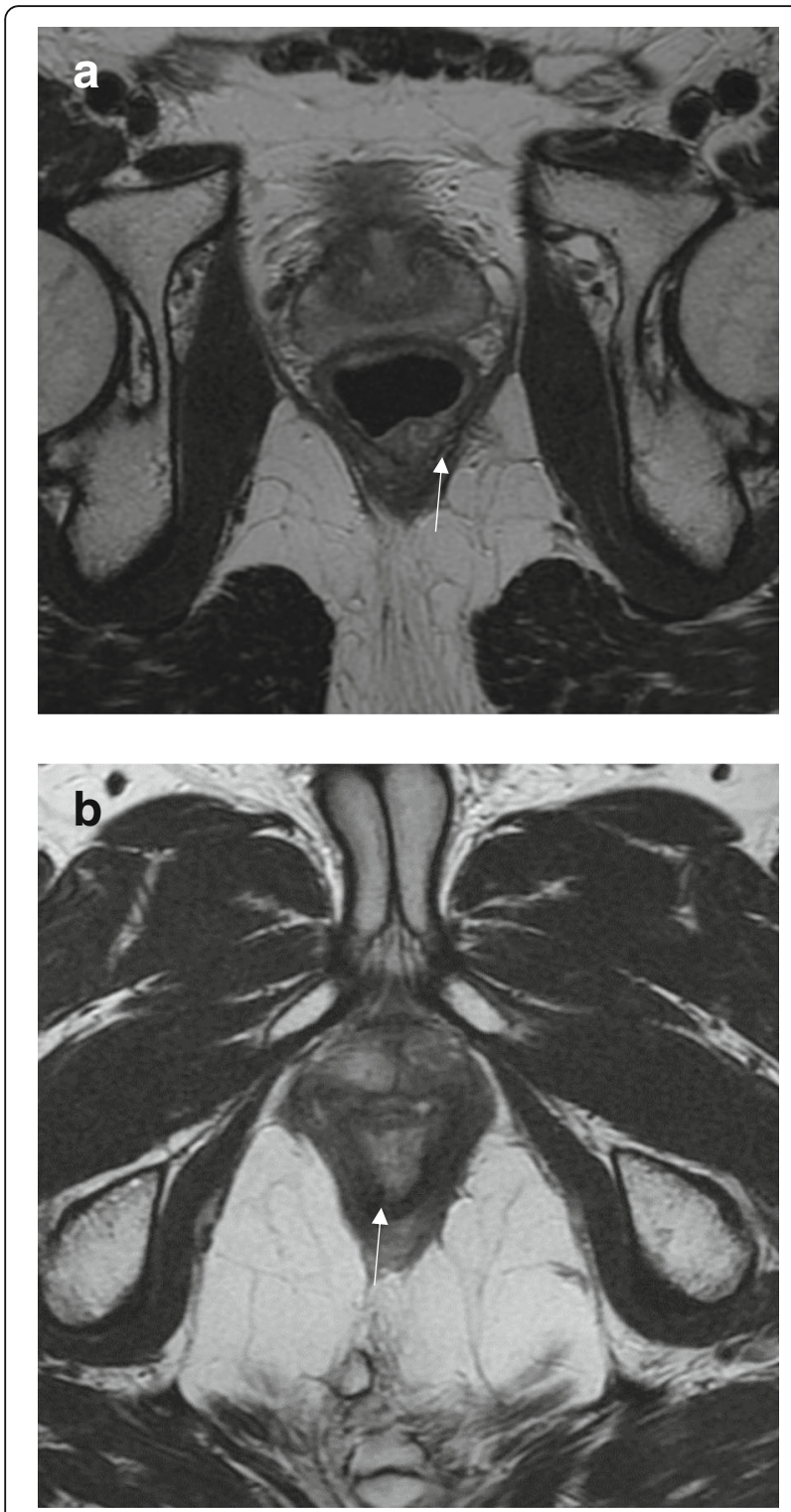

Fig. 17 Near-complete responses. a Restaging after 14 weeks of neoadjuvant CRT completion shows minimal residual high signal intensity lesion within the low rectal scar. Transanal endoscopic microsurgery (full-thickness local excision) was performed showing ypT1 lesion. b Follow-up exam after local excision shows the normalappearing low signal intensity posterior scar (arrow)

salvage resection. Local recurrence after nCRT and local excision may manifest as tumor intermediate signal intensity growing along the scar [22, 80]. Inflammatory changes may overlap tumor recurrence; therefore, serial exams might help in detecting tumor-related changes (Fig. 18). These recurrences are often close to the mesorectal fascia which may increase the risks of a R1 salvage resection and a definitive stoma [79].

In summary, after nCRT, the roles of MRI in organ-preserving management after nCRT are

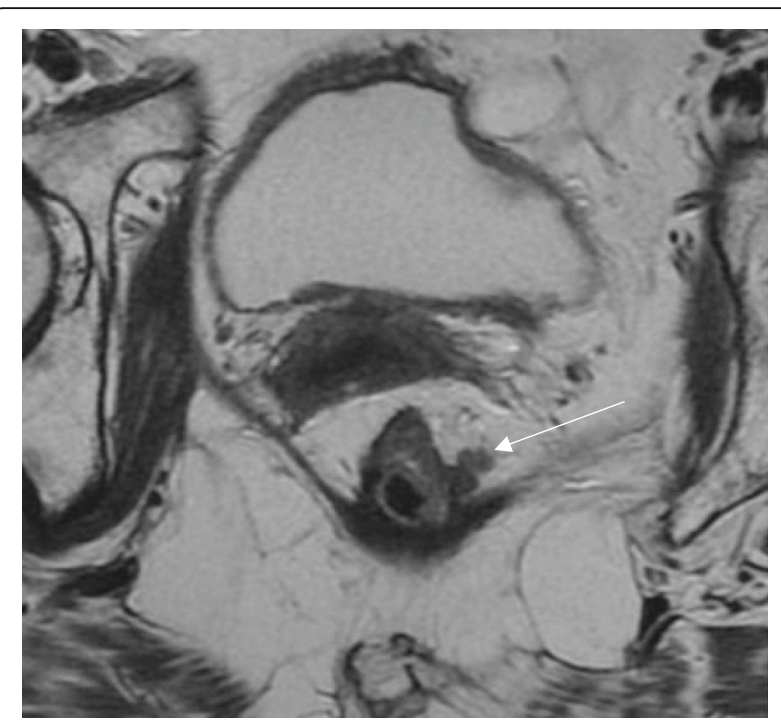

Fig. 18 Recurrence after local excision. High-resolution T2WI followup exam 5 years after local excision performed due to residual small lesion after CRT shows recurrent nodular lesion growing along the left rectal wall (arrow). The patient was medically unfit and aged 81 years old. Even though radical surgery was recommended, the patient refused salvage resection

1) Selecting complete responders amenable to surveillance in a watch-and-wait program

2) Selecting good responders that might be reassessed later to reach for a complete clinical response

3) Selecting good responders with no extraluminal disease and small residual lesion eligible to local excision

4) Follow-up of those patients to detect regrowths or recurrences

\section{Conclusions}

Organ-preserving strategies in rectal cancer are evolving as the balance between oncologic and functional outcomes are a major concern to the multidisciplinary team. Patient selection is critical to the successful management of the disease, and proper staging and reassessment of tumor response (restaging) may not only improve oncologic outcomes but also avoid overtreatment.

The radiologist plays a central role in management decisions and must be aware of the idiosyncratic risks of less-invasive approaches. Future perspectives involve molecular predictors of tumor response, the development of prospective trials, and the analysis of multicentric international database that provide more knowledge so that guidelines adopt changes to clinical practice with evidence-based data.

\section{Abbreviations}

$\geq$ pT3: Tumors invading beyond the muscularis propria;

APR: Abdominoperineal resection; cCR: Complete clinical response;

CRM: Circumferential resection margin; CRT: Chemoradiation; DRE: Digital 
rectum exam; DWI: Diffusion-weighted MR imaging; MRI: Magnetic resonance imaging; nCRT: Neoadjuvant chemoradiation; pCR: Complete pathological response; $\mathrm{pN}+$ : Mesorectal nodal metastases; TME: Total mesorectal excision; TRG: Tumor regression grade

\section{Funding}

This work has not received any funding.

\section{Availability of data and materials}

No datasets were generated or analyzed.

\section{Authors' contributions}

Both authors read and approved the final manuscript.

\section{Ethics approval and consent to participate}

Not applicable

\section{Consent for publication}

Not applicable

\section{Competing interests}

The authors declare that they have no competing interests.

\section{Publisher's Note}

Springer Nature remains neutral with regard to jurisdictional claims in published maps and institutional affiliations.

\section{Author details}

${ }^{1}$ School of Medicine, Radiology Department, University of São Paulo, Travessa da Rua Dr. Ovídio Pires de Campos, 75, São Paulo 05403-010, Brazil. ${ }^{2}$ Angelita \& Joaquim Gama Institute, São Paulo, Brazil. ${ }^{3}$ School of Medicine, Colorectal Surgery Division, University of São Paulo, São Paulo, Brazil. ${ }^{4}$ Ludwig Institute for Cancer Research São Paulo Branch, São Paulo, Brazil.

Received: 8 January 2019 Accepted: 5 April 2019

Published online: 30 May 2019

\section{References}

1. Sauer R, Becker $H$, Hohenberger W et al (2004) Preoperative versus postoperative chemoradiotherapy for rectal cancer. N Engl J Med 351(17): $1731-1740$

2. Kapiteijn E, Marijnen CA, Nagtegaal ID et al (2001) Preoperative radiotherapy combined with total mesorectal excision for resectable rectal cancer. N Engl J Med 345(9):638-646

3. Sebag-Montefiore D, Stephens RJ, Steele R et al (2009) Preoperative radiotherapy versus selective postoperative chemoradiotherapy in patients with rectal cancer (MRC CR07 and NCIC-CTG C016): a multicentre, randomised trial. Lancet 373(9666):811-820

4. Martling A, Holm T, Johansson H, Rutqvist LE, Cedermark B; Stockholm Colorectal Cancer Study Group (2001) The Stockholm II trial on preoperative radiotherapy in rectal carcinoma: long-term follow-up of a population-based study. Cancer 92(4):896-902

5. Loos M, Quentmeier P, Schuster T et al (2013) Effect of preoperative radio(chemo)therapy on long-term functional outcome in rectal cancer patients: a systematic review and meta-analysis. Ann Surg Oncol 20(6):1816-1828

6. Birgisson H, Påhlman L, Gunnarsson U, Glimelius B; Swedish Rectal Cancer Trial Group (2005) Adverse effects of preoperative radiation therapy for rectal cancer: long-term follow-up of the Swedish Rectal Cancer Trial. J Clin Oncol 23(34):8697-8705

7. Den Oudsten BL, Traa MJ, Thong MS et al (2012) Higher prevalence of sexual dysfunction in colon and rectal cancer survivors compared with the normative population: a population-based study. Eur J Cancer 48(17):3161-3170

8. Emmertsen KJ, Laurberg S (2012) Low anterior resection syndrome score: development and validation of a symptom-based scoring system for bowel dysfunction after low anterior resection for rectal cancer. Ann Surg 255(5):922-928

9. Habr-Gama A, Perez RO, Nadalin W et al (2004) Operative versus nonoperative treatment for stage 0 distal rectal cancer following chemoradiation therapy: long-term results. Ann Surg 240(4):711-717 discussion 7-8
10. Habr-Gama A, Sabbaga J, Gama-Rodrigues J et al (2013) Watch and wait approach following extended neoadjuvant chemoradiation for distal rectal cancer: are we getting closer to anal cancer management? Dis Colon Rectum 56(10):1109-1117

11. Habr-Gama A, Sao Juliao GP, Vailati BB et al (2019) Organ preservation in cT2N0 rectal cancer after neoadjuvant chemoradiation therapy: the impact of radiation therapy dose-escalation and consolidation chemotherapy. Ann Surg 269(1):102-107

12. Rullier E, Rouanet $P$, Tuech JJ et al (2017) Organ preservation for rectal cancer (GRECCAR 2): a prospective, randomised, open-label, multicentre, phase 3 trial. Lancet 390(10093):469-479

13. Bach SP, Hill J, Monson JR et al (2009) A predictive model for local recurrence after transanal endoscopic microsurgery for rectal cancer. $\mathrm{Br} J$ Surg 96(3):280-290

14. Garcia-Aguilar J, Renfro LA, Chow OS et al (2015) Organ preservation for clinical T2NO distal rectal cancer using neoadjuvant chemoradiotherapy and local excision (ACOSOG Z6041): results of an open-label, single-arm, multiinstitutional, phase 2 trial. Lancet Oncol 16(15):1537-1546

15. Brown G, Richards CJ, Newcombe RG et al (1999) Rectal carcinoma: thinsection MR imaging for staging in 28 patients. Radiology 211(1):215-222

16. MERCURY Study Group (2007) Extramural depth of tumor invasion at thinsection MR in patients with rectal cancer: results of the MERCURY study. Radiology 243(1):132-139

17. Brown G, Radcliffe AG, Newcombe RG, Dallimore NS, Bourne MW, Williams GT (2003) Preoperative assessment of prognostic factors in rectal cancer using high-resolution magnetic resonance imaging. Br J Surg 90(3):355-364

18. Taylor FG, Quirke P, Heald RJ et al (2011) Preoperative high-resolution magnetic resonance imaging can identify good prognosis stage I, II, and III rectal cancer best managed by surgery alone: a prospective, multicenter, European study. Ann Surg 253(4):711-719

19. Burton S, Brown G, Daniels IR et al (2006) MRI directed multidisciplinary team preoperative treatment strategy: the way to eliminate positive circumferential margins? Br J Cancer 94(3):351-357

20. Glynne-Jones R, Wyrwicz L, Tiret E et al (2017) Rectal cancer: ESMO Clinical Practice Guidelines for diagnosis, treatment and follow-up. Ann Oncol 28(suppl 4):iv22-iv40

21. Beets-Tan RG, Beets GL, Vliegen RF et al (2001) Accuracy of magnetic resonance imaging in prediction of tumour-free resection margin in rectal cancer surgery. Lancet 357(9255):497-504

22. Vliegen RF, Beets GL, Lammering G et al (2008) Mesorectal fascia invasion after neoadjuvant chemotherapy and radiation therapy for locally advanced rectal cancer: accuracy of MR imaging for prediction. Radiology 246(2):454-462

23. Bhoday J, Balyasnikova S, Wale A, Brown G (2017) How should imaging direct/ orient management of rectal cancer? Clin Colon Rectal Surg 30(5):297-312

24. Taylor FG, Quirke P, Heald RJ et al (2014) Preoperative magnetic resonance imaging assessment of circumferential resection margin predicts diseasefree survival and local recurrence: 5-year follow-up results of the MERCURY study. J Clin Oncol 32(1):34-43

25. Heald RJ (1988) The 'Holy Plane' of rectal surgery. J R Soc Med 81(9):503-508

26. Heald RJ, Husband EM, Ryall RD (1982) The mesorectum in rectal cancer surgery--the clue to pelvic recurrence? Br J Surg 69(10):613-616

27. Heald RJ, Ryall RD (1986) Recurrence and survival after total mesorectal excision for rectal cancer. Lancet 1(8496):1479-1482

28. Heald RJ, Moran BJ, Ryall RD, Sexton R, MacFarlane JK (1998) Rectal cancer: the Basingstoke experience of total mesorectal excision, 1978-1997. Arch Surg 133(8):894-899

29. Albert MR, Atallah SB, de Beche-Adams TC, Izfar S, Larach SW (2013) Transanal minimally invasive surgery (TAMIS) for local excision of benign neoplasms and early-stage rectal cancer: efficacy and outcomes in the first 50 patients. Dis Colon Rectum 56(3):301-307

30. Lezoche E, Baldarelli M, Lezoche G, Paganini AM, Gesuita R, Guerrieri M (2012) Randomized clinical trial of endoluminal locoregional resection versus laparoscopic total mesorectal excision for T2 rectal cancer after neoadjuvant therapy. Br J Surg 99(9):1211-1218

31. Saraste D, Gunnarsson U, Janson M (2013) Predicting lymph node metastases in early rectal cancer. Eur J Cancer 49(5):1104-1108

32. Balyasnikova S, Read J, Wotherspoon A et al (2017) Diagnostic accuracy of highresolution MRI as a method to predict potentially safe endoscopic and surgical planes in patients with early rectal cancer. BMJ Open Gastroenterol 4(1):e000151

33. Hompes R, Cunningham C (2011) Extending the role of Transanal Endoscopic Microsurgery (TEM) in rectal cancer. Colorectal Dis 13(Suppl 7):32-36 
34. Kikuchi R, Takano M, Takagi K et al (1995) Management of early invasive colorectal cancer. Risk of recurrence and clinical guidelines. Dis Colon Rectum 38(12):1286-1295

35. Tanaka S, Kaltenbach T, Chayama K, Soetikno R (2006) High-magnification colonoscopy (with videos). Gastrointest Endosc 64(4):604-613

36. Allaix ME, Arezzo A, Morino M (2016) Transanal endoscopic microsurgery for rectal cancer: $\mathrm{T1}$ and beyond? An evidence-based review. Surg Endosc 30(11):4841-4852

37. Brown G, Davies S, Williams GT et al (2004) Effectiveness of preoperative staging in rectal cancer: digital rectal examination, endoluminal ultrasound or magnetic resonance imaging? Br J Cancer 91(1):23-29

38. Wada Y, Kashida H, Kudo SE, Misawa M, Ikehara N, Hamatani S (2010) Diagnostic accuracy of pit pattern and vascular pattern analyses in colorectal lesions. Dig Endosc 22(3):192-199

39. Smith N, Brown G (2008) Preoperative staging of rectal cancer. Acta Oncol 47(1):20-31

40. Smith NJ, Barbachano Y, Norman AR, Swift RI, Abulafi AM, Brown G (2008) Prognostic significance of magnetic resonance imaging-detected extramural vascular invasion in rectal cancer. Br J Surg 95(2):229-236

41. Greenberg JA, Shibata D, Herndon JE 2nd, Steele GD Jr, Mayer R, Bleday R (2008) Local excision of distal rectal cancer: an update of cancer and leukemia group B 8984. Dis Colon Rectum 51(8):1185-1191 discussion 91-4

42. Hompes R, McDonald R, Buskens C et al (2013) Completion surgery following transanal endoscopic microsurgery: assessment of quality and short- and longterm outcome. Colorectal Dis 15(10):e576-e581

43. Shihab OC, Moran BJ, Heald RJ, Quirke P, Brown G (2009) MRI staging of low rectal cancer. Eur Radiol 19(3):643-650

44. Shihab OC, Heald RJ, Rullier E et al (2009) Defining the surgical planes on MRI improves surgery for cancer of the low rectum. Lancet Oncol 10(12):1207-1211

45. Rullier E, Denost Q, Vendrely V, Rullier A, Laurent C (2013) Low rectal cancer: classification and standardization of surgery. Dis Colon Rectum 56(5):560-567

46. Battersby NJ, How P, Moran B et al (2016) Prospective validation of a low rectal cancer magnetic resonance imaging staging system and development of a local recurrence risk stratification model: the MERCURY II study. Ann Surg 263(4):751-760

47. Dattani M, Heald RJ, Goussous G et al (2018) Oncological and survival outcomes in watch and wait patients with a clinical complete response after neoadjuvant chemoradiotherapy for rectal cancer: a systematic review and pooled analysis. Ann Surg 268(6):955-967

48. Habr-Gama A, Perez RO, Wynn G, Marks J, Kessler H, Gama-Rodrigues (2010) Complete clinical response after neoadjuvant chemoradiation therapy for distal rectal cancer: characterization of clinical and endoscopic findings for standardization. Dis Colon Rectum 53(12):1692-1698

49. Bernier L, Balyasnikova S, Tait D, Brown G (2018) Watch-and-wait as a therapeutic strategy in rectal cancer. Curr Colorectal Cancer Rep 14(2):37-55

50. Beets GL, Figueiredo NF, Beets-Tan RG (2017) Management of rectal cancer without radical resection. Annu Rev Med 68:169-182

51. Habr-Gama A, Perez RO, Proscurshim I et al (2008) Interval between surgery and neoadjuvant chemoradiation therapy for distal rectal cancer: does delayed surgery have an impact on outcome? Int J Radiat Oncol Biol Phys 71(4):1181-1188

52. Habr-Gama A, São Julião GP, Gama-Rodrigues J, Vailati BB, Ortega C, Fernandez LM et al (2017) Baseline T classification predicts early tumo regrowth after nonoperative management in distal rectal cancer after extended neoadjuvant chemoradiation and initial complete clinical response. Dis Colon Rectum 60(6):586-594

53. Chadi SA, Malcomson L, Ensor J et al (2018) Factors affecting local regrowth after watch and wait for patients with a clinical complete response following chemoradiotherapy in rectal cancer (InterCoRe consortium): an individual participant data meta-analysis. Lancet Gastroenterol Hepatol 3(12):825-836

54. Habr-Gama A, Sao Juliao GP, Vailati BB et al (2019) Organ preservation among patients with clinically node-positive rectal cancer: is it really more dangerous? Dis Colon Rectum, Epub ahead of print https://doi.org/10.1097/ DCR.0000000000001337

55. Sao Juliao GP, Habr-Gama A, Vailati BB, Perez RO (2017) The good, the bad and the ugly: rectal cancers in the twenty-first century. Tech Coloproctol 21(7):573-575

56. Appelt AL, Pløen J, Harling $\mathrm{H}$ et al (2015) High-dose chemoradiotherapy and watchful waiting for distal rectal cancer: a prospective observational study. Lancet Oncol 16(8):919-927
57. Habr-Gama A, Perez RO, Sabbaga J, Nadalin W, São Julião GP, GamaRodriques J (2009) Increasing the rates of complete response to neoadjuvant chemoradiotherapy for distal rectal cancer: results of a prospective study using additional chemotherapy during the resting period. Dis Colon Rectum 52(12):1927-1934

58. Sao Juliao GP, Habr-Gama A, Vailati BB et al (2018) Is neoadjuvant chemoradiation with dose-escalation and consolidation chemotherapy sufficient to increase surgery-free and distant metastases-free survival in baseline cT3 rectal cancer? Eur J Surg Oncol 44(1):93-99

59. Lefevre $\mathrm{JH}$, Mineur $\mathrm{L}$, Kotti $\mathrm{S}$ et al (2016) Effect of interval (7 or 11 weeks) between neoadjuvant radiochemotherapy and surgery on complete pathologic response in rectal cancer: a multicenter, randomized, controlled trial (GRECCAR-6). J Clin Oncol 34(31):3773-3780

60. Patel UB, Blomqvist LK, Taylor F et al (2012) MRI after treatment of locally advanced rectal cancer: how to report tumor response--the MERCURY experience. AJR Am J Roentgenol 199(4):W486-W495

61. Lambregts DM, Rao SX, Sassen S et al (2015) MRI and diffusion-weighted MRI volumetry for identification of complete tumor responders after preoperative chemoradiotherapy in patients with rectal cancer: a bi-institutional validation study. Ann Surg 262(6):1034-1039

62. Lambregts DM, Maas M, Bakers FC et al (2011) Long-term follow-up features on rectal MRI during a wait-and-see approach after a clinical complete response in patients with rectal cancer treated with chemoradiotherapy. Dis Colon Rectum 54(12):1521-1528

63. Engelen SM, Beets-Tan RG, Lahaye MJ et al (2010) MRI after chemoradiotherapy of rectal cancer: a useful tool to select patients for local excision. Dis Colon Rectum 53(7):979-986

64. Lambregts DM, Lahaye MJ, Heijnen LA et al (2016) MRI and diffusionweighted MRI to diagnose a local tumour regrowth during long-term follow-up of rectal cancer patients treated with organ preservation after chemoradiotherapy. Eur Radiol 26(7):2118-2125

65. Habr-Gama A, Perez RO, Proscurshim I et al (2006) Patterns of failure and survival for nonoperative treatment of stage c0 distal rectal cancer following neoadjuvant chemoradiation therapy. J Gastrointest Surg 10(10): 1319-1328 discussion 28-9

66. Hupkens BJP, Maas M, Martens MH et al (2018) Organ preservation in rectal cancer after chemoradiation: should we extend the observation period in patients with a clinical near-complete response? Ann Surg Oncol 25(1):197203

67. van der Valk MJM, Hilling DE, Bastiaannet E et al (2018) Long-term outcomes of clinical complete responders after neoadjuvant treatment for rectal cancer in the International Watch \& Wait Database (IMWD): an international multicentre registry study. Lancet 391(10139):2537-2545

68. Beets GL, Figueiredo NL, Habr-Gama A, van de Velde CJ (2015) A new paradigm for rectal cancer: Organ preservation: Introducing the International Watch \& WaitDatabase (IWWD). Eur J Surg Oncol 41(12):1562-4 https://doi.org/10.1016/j.ejso.2015.09.008

69. Perez RO, Habr-Gama A, São Julião GP et al (2012) Optimal timing for assessment of tumor response to neoadjuvant chemoradiation in patients with rectal cancer: do all patients benefit from waiting longer than 6 weeks? Int J Radiat Oncol Biol Phys 84(5):1159-1165

70. Habr-Gama A, São Julião GP, Fernandez LM et al (2019) Achieving a complete clinical response after neoadjuvant chemoradiation that does not require surgical resection: it may take longer than you think! Dis Colon Rectum https:// doi.org/10.1097/DCR.0000000000001338, Epub ahead of print

71. Bhoday J, Smith F, Siddiqui MR et al (2016) Magnetic resonance tumor regression grade and residual mucosal abnormality as predictors for pathological complete response in rectal cancer postneoadjuvant chemoradiotherapy. Dis Colon Rectum 59(10):925-933

72. Patel UB, Brown G, Rutten $\mathrm{H}$ et al (2012) Comparison of magnetic resonance imaging and histopathological response to chemoradiotherapy in locally advanced rectal cancer. Ann Surg Oncol 19(9):2842-2852

73. Patel UB, Taylor F, Blomqvist $L$ et al (2011) Magnetic resonance imagingdetected tumor response for locally advanced rectal cancer predicts survival outcomes: MERCURY experience. J Clin Oncol 29(28):3753-3760

74. Lambregts DM, Vandecaveye $V$, Barbaro B et al (2011) Diffusion-weighted MRI for selection of complete responders after chemoradiation for locally advanced rectal cancer: a multicenter study. Ann Surg Oncol 18(8):2224-2231

75. Sloothaak DA, Geijsen DE, van Leersum NJ et al (2013) Optimal time interval between neoadjuvant chemoradiotherapy and surgery for rectal cancer. $\mathrm{Br}$ J Surg 100(7):933-939 
76. Petrelli F, Sgroi G, Sarti E, Barni S (2016) Increasing the interval between neoadjuvant chemoradiotherapy and surgery in rectal cancer: a metaanalysis of published studies. Ann Surg 263(3):458-464

77. Habr-Gama A, Gama-Rodrigues J, Sao Juliao GP et al (2014) Local recurrence after complete clinical response and watch and wait in rectal cancer after neoadjuvant chemoradiation: impact of salvage therapy on local disease control. Int J Radiat Oncol Biol Phys 88(4):822-828

78. Perez RO, Habr-Gama A, Lynn PB et al (2013) Transanal endoscopic microsurgery for residual rectal cancer (ypT0-2) following neoadjuvant chemoradiation therapy: another word of caution. Dis Colon Rectum 56(1):6-13

79. Perez RO, Habr-Gama A, Sao Juliao GP et al (2016) Transanal endoscopic microsurgery (TEM) following neoadjuvant chemoradiation for rectal cancer: outcomes of salvage resection for local recurrence. Ann Surg Oncol 23(4): $1143-1148$

80. São Julião GP, Ortega CD, Vailati BB et al (2017) Magnetic resonance imaging following neoadjuvant chemoradiation and transanal endoscopic microsurgery for rectal cancer. Colorectal Dis 19(6):0196-0203

\section{Submit your manuscript to a SpringerOpen ${ }^{\circ}$ journal and benefit from:}

- Convenient online submission

- Rigorous peer review

- Open access: articles freely available online

High visibility within the field

- Retaining the copyright to your article

Submit your next manuscript at $\boldsymbol{\nabla}$ springeropen.com 